\title{
$20 \mathrm{~Gb} / \mathrm{s}$ Modulation of Silicon-Integrated Short- Wavelength Hybrid-Cavity VCSELs
}

\author{
Emanuel P. Haglund, Student Member, IEEE, Sulakshna Kumari, Petter Westbergh, \\ Johan S. Gustavsson, Roel G. Baets, Fellow, IEEE, Gunther Roelkens, Member, IEEE, \\ and Anders Larsson, Fellow, IEEE
}

\begin{abstract}
We investigate the dynamics of silicon-integrated 850-nm-wavelength hybrid-cavity vertical-cavity surfaceemitting lasers (VCSELs). The VCSELs consist of a GaAs-based "half-VCSEL" attached to a dielectric distributed Bragg reflector on a silicon substrate using ultra-thin divinylsiloxanebis-benzocyclobutene adhesive bonding. A $5 \mu \mathrm{m}$ oxide aperture diameter VCSEL, with a small signal modulation bandwidth of $11 \mathrm{GHz}$, supports data transmission at bit rates up to $20 \mathrm{~Gb} / \mathrm{s}$. The modulation bandwidth and the large signal modulation characteristics are found to be impaired by the high thermal impedance.
\end{abstract}

Index Terms-High-speed modulation, large signal modulation, optical interconnects, semiconductor lasers, silicon photonics, vertical cavity surface-emitting laser (VCSEL).

\section{INTRODUCTION}

$\mathrm{S}_{\mathrm{fien}}^{\mathrm{II}}$ LICON photonics has emerged as a promising technology for future optical interconnects. Silicon's lack of efficient light emission calls for hybrid solutions. GaAs-based verticalcavity surface-emitting lasers (VCSELs) are the most highspeed and energy-efficient light sources available with modulation bandwidth up to $30 \mathrm{GHz}$ [1], data rates above $70 \mathrm{~Gb} / \mathrm{s}$ [2], and energy dissipation of less than $100 \mathrm{fJ} / \mathrm{bit}$ at data rates up to $50 \mathrm{~Gb} / \mathrm{s}$ [1], [3].

A promising technique for integration of VCSELs on silicon is heterogeneous integration. This has previously been successfully demonstrated using InP-based structures attached to a silicon high-contrast grating on a silicon substrate [4], [5]. To date, small signal modulation bandwidths up to $2.5 \mathrm{GHz}$ and large signal data transmission at bit rates up to $5 \mathrm{~Gb} / \mathrm{s}$ have been demonstrated with heterogeneously integrated VCSELs [5].

Recently, we demonstrated a silicon-integrated shortwavelength hybrid-cavity VCSEL, as a potential light source

Manuscript received September 9, 2015. This work was supported in part by the Swedish Foundation for Strategic Research and in part by the FP7ERC-InSpectra Advanced Grant.

Emanuel P. Haglund, Petter Westbergh, Johan S. Gustavsson, and Anders Larsson are with the Photonics Laboratory, Department of Microtechnology and Nanoscience, Chalmers University of Technology, SE-412 96 Göteborg, Sweden (e-mail: emanuel.haglund@chalmers.se).

Sulakshna Kumari, Roel G. Baets, and Gunther Roelkens are with the Photonics Research Group - Center for Nano- and Biophotonics (NBPhotonics), Sint-Pietersnieuwstraat 41, B-9000 Gent, Belgium. for silicon nitride waveguide circuits, where a GaAs-based "half-VCSEL" is attached to a dielectric distributed Bragg reflector (DBR) on a silicon substrate [6]. Here, we extend the analysis of the hybrid-cavity VCSEL to an investigation of its dynamic characteristics. A VCSEL with $5 \mu \mathrm{m}$ oxide aperture diameter, having a small signal modulation bandwidth exceeding $11 \mathrm{GHz}$, is used to transfer data at bit rates up to $20 \mathrm{~Gb} / \mathrm{s}$. The high thermal impedance is found to have a strong impact on the dynamics.

The paper is organized as follows. Section II covers the VCSEL design and the static characteristics, whereas the small signal modulation response and an analysis of speed limitations are presented in Section III. Large signal data transmission experiments are presented in Section IV and the paper is concluded in Section V.

\section{VCSEL DESIGN AND STATIC ChARACTERISTICS}

The 850-nm-wavelength hybrid-cavity VCSEL design is illustrated in Fig. 1. The "half-VCSEL" epitaxial structure was grown on a GaAs substrate (at IQE Europe Ltd.) in the following order: a 23 pair $p$-doped $\mathrm{Al}_{0.90} \mathrm{Ga}_{0.10} \mathrm{As} / \mathrm{Al}_{0.12} \mathrm{Ga}_{0.88} \mathrm{As}$ DBR with an embedded $30 \mathrm{~nm}$ thick $\mathrm{Al}_{0.98} \mathrm{Ga}_{0.02}$ As layer to enable the formation of an oxide aperture, an active region with five $4 \mathrm{~nm}$ thick $\mathrm{In}_{0.10} \mathrm{Ga}_{0.90} \mathrm{As}$ quantum wells, and an $n$-doped $\mathrm{Al}_{0.12} \mathrm{Ga}_{0.88}$ As intra-cavity contact and current spreading layer. After adhesive bonding to the 20 pair $\mathrm{SiO}_{2} / \mathrm{Ta}_{2} \mathrm{O}_{5}$ dielectric DBR on a silicon wafer using ultra-thin $(40 \mathrm{~nm})$ divinylsiloxane-bis-benzocyclobutene (DVS-BCB) adhesive bonding [7], and removal of the GaAs substrate, VCSEL devices were fabricated using a standard process for GaAs-based oxide-confined VCSELs. A thick layer of spin-coated BCB was used under the bondpads for low pad capacitance. A detailed description of the design and fabrication is presented in [6].

All measurements were performed with the VCSELs on a temperature-controlled heat-sink held at $25^{\circ} \mathrm{C}$. The lightcurrent-voltage characteristics of hybrid-cavity VCSELs with oxide aperture diameters of 3,5 , and $7 \mu \mathrm{m}$ are shown in Fig. 2. The emission spectrum for the $5 \mu \mathrm{m}$ aperture VCSEL, biased at $3.5 \mathrm{~mA}$, is included as an inset to Fig. 2, showing lasing at multiple transverse modes around $845 \mathrm{~nm}$. The threshold current is as low as $0.22 \mathrm{~mA}$ for the $3 \mu \mathrm{m}$ oxide aperture VCSEL and the slope efficiency is $\sim 0.25 \mathrm{~W} / \mathrm{A}$ for all aperture sizes, providing a maximum optical output power of 


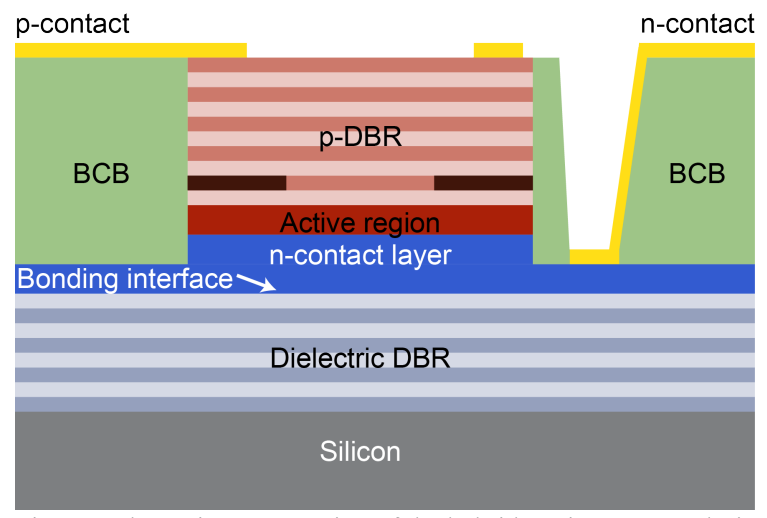

Fig. 1. Schematic cross-section of the hybrid-cavity VCSEL design.

$0.74 \mathrm{~mW}$ for the $7 \mu \mathrm{m}$ oxide aperture VCSEL. Table I summarizes the static characteristics. In contrast to the VCSELs presented in [6], where the topmost layer in the $p$ DBR has a thickness larger than $\lambda / 4$ for achieving a slightly out-of-phase reflection at the semiconductor-air interface to boost the slope efficiency and the output power (reduced photon lifetime [8]), these VCSELs have a standard $\lambda / 4$ thick top layer. Therefore, the threshold currents, slope efficiencies, and the maximum output powers are somewhat lower. The longer photon lifetime was found to be essential for achieving sufficient damping of the modulation response under large signal modulation and data transmission [9].

As can be seen in Fig. 2, the VCSEL output power suffers from an early onset of the thermal rollover, attributed to the limited heat transport through the dielectric DBR to the silicon substrate. The thermal impedance of the $5 \mu \mathrm{m}$ oxide aperture VCSEL is $10.7 \mathrm{~K} / \mathrm{mW}$, measured by tracking the redshift of the fundamental optical mode with dissipated power and stage temperature. The thermal impedance is thus $\sim 3$ times higher than for ordinary GaAs-based oxide-confined VCSELs [10].

\section{SMall Signal Modulation Response}

The small signal modulation response $\left(\mathrm{S}_{21}\right)$ was measured with a $20 \mathrm{GHz}$ vector network analyzer (Agilent N5230A) connected to the VCSEL under test through a high-speed bias-T and a high-speed RF probe (Picoprobe 40A-GSG100P). The VCSEL was butt-coupled to an OM4 multimode optical fiber connected to a $28 \mathrm{GHz}$ photodetector (Picometrix DG-32xr-FC). The measured data was corrected for the frequency response of the probe and photodetector.

Measured small signal modulation responses for the 3, 5, and $7 \mu \mathrm{m}$ oxide aperture VCSELs are shown in Fig. 3 at four different bias currents. We attribute the low frequency roll-off of the modulation response, which is particularly pronounced at low bias currents, to overdamping from spatial hole burning [11]. The maximum $3 \mathrm{~dB}$ bandwidth, achieved at the highest bias currents indicated, is $11.7,11.4$, and $10.4 \mathrm{GHz}$ for VCSELs with 3,5 , and $7 \mu \mathrm{m}$ oxide aperture diameter, respectively.

By fitting a three-pole transfer function to the measured modulation response, the resonance frequency and the damping rate can be extracted [12]. These can then be used to calculate the $K$ - and $D$-factors, as shown in Fig. 4. The $K$ -

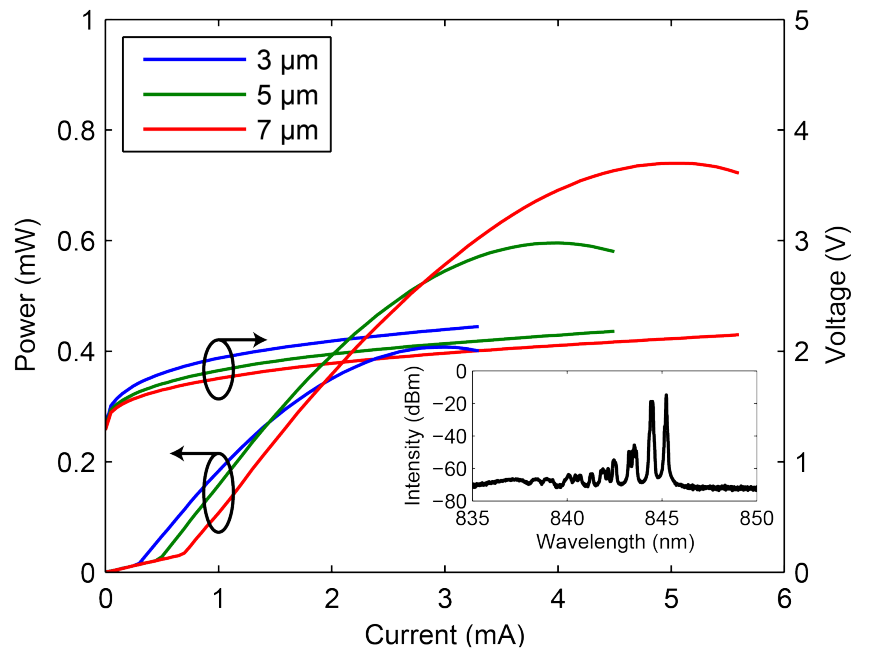

Fig. 2. Light-current-voltage characteristics measured at $25^{\circ} \mathrm{C}$ for hybridcavity VCSELs with oxide aperture diameters of 3, 5, and $7 \mu \mathrm{m}$. Inset: Emission spectrum for the $5 \mu \mathrm{m}$ VCSEL biased at $3.5 \mathrm{~mA}$.

TABLE I STATIC PERFORMANCE PARAMETERS

\begin{tabular}{|c|c|c|c|c|c|}
\hline 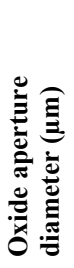 & 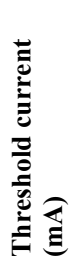 & 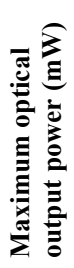 & 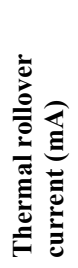 & 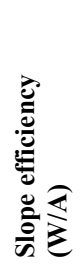 & 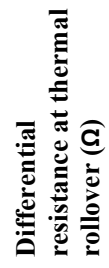 \\
\hline 3 & 0.22 & 0.41 & 3.4 & 0.23 & 88 \\
\hline 5 & 0.38 & 0.60 & 4.0 & 0.25 & 73 \\
\hline 7 & 0.57 & 0.74 & 5.0 & 0.25 & 59 \\
\hline
\end{tabular}

factors are $0.2 \mathrm{~ns}$ for all three oxide aperture sizes, whereas the $D$-factors scale with the inverse of the aperture diameter and are $12.7,7.2$, and $5.9 \mathrm{GHz} / \mathrm{mA}^{1 / 2}$ for VCSELs with 3,5 , and $7 \mu \mathrm{m}$ oxide aperture diameter, respectively. From the fit of the transfer function, a $5-6 \mathrm{GHz}$ parasitic pole was also extracted. The low parasitic cut-off frequency is attributed to the high capacitance across the single oxide layer used in this VCSEL design and could thus be reduced by including additional oxide layers [13]-[15].

The intrinsic damping limited modulation bandwidth $\left(f_{3 \mathrm{~dB}, \mathrm{damping}}\right)$, in the absence of parasitics and thermal effects, estimated from [12]

$$
f_{3 \mathrm{~dB}, \text { damping }}=2 \pi \sqrt{2} / \mathrm{K}
$$

exceeds $40 \mathrm{GHz}$. On the other hand, the thermally limited bandwidth $\left(f_{3 \mathrm{~dB}, \text { thermal }}\right)$, estimated from [12]

$$
f_{3 \mathrm{~dB}, \text { thermal }}=\sqrt{1+\sqrt{2}} \cdot f_{\mathrm{r}, \text { max }}
$$

where $f_{\mathrm{r}, \max }$ is the maximum resonance frequency, is only $16 \mathrm{GHz}$ for the $5 \mu \mathrm{m}$ aperture VCSEL. This is due to the early onset of the thermal rollover which prevents a sufficiently high photon density from being established in the cavity. With the resonance frequency $\left(f_{\mathrm{r}}\right)$ increasing with the photon density $(S)$ according to [12] 


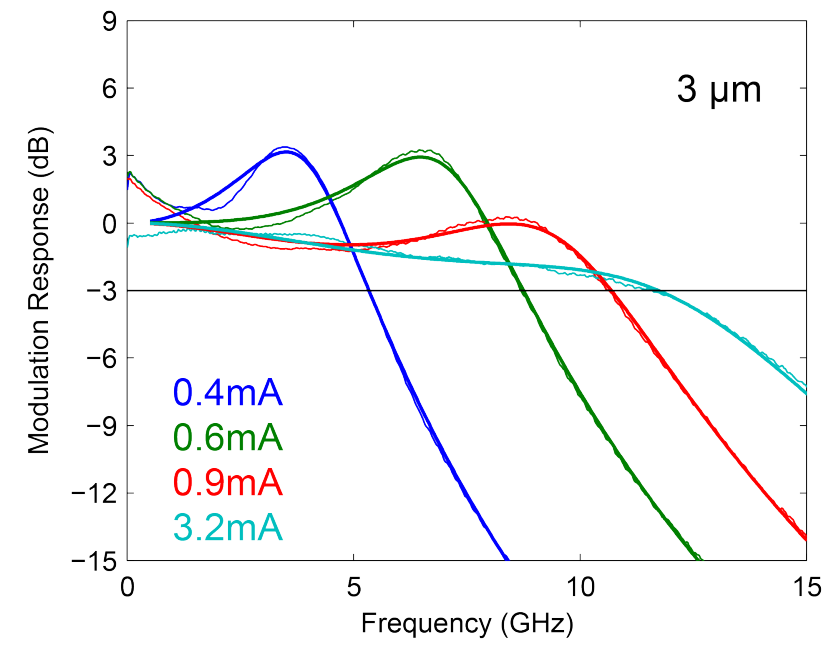

(a)

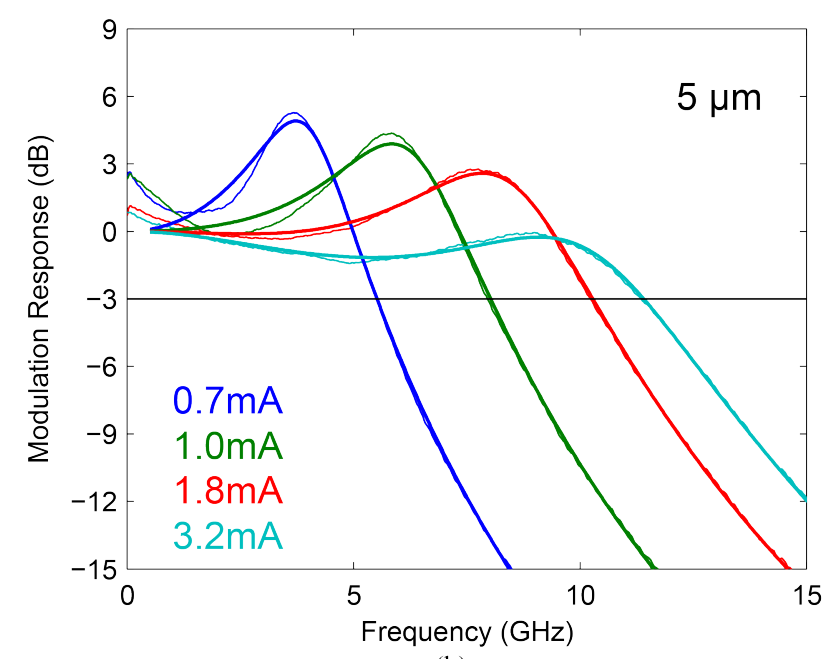

(b)

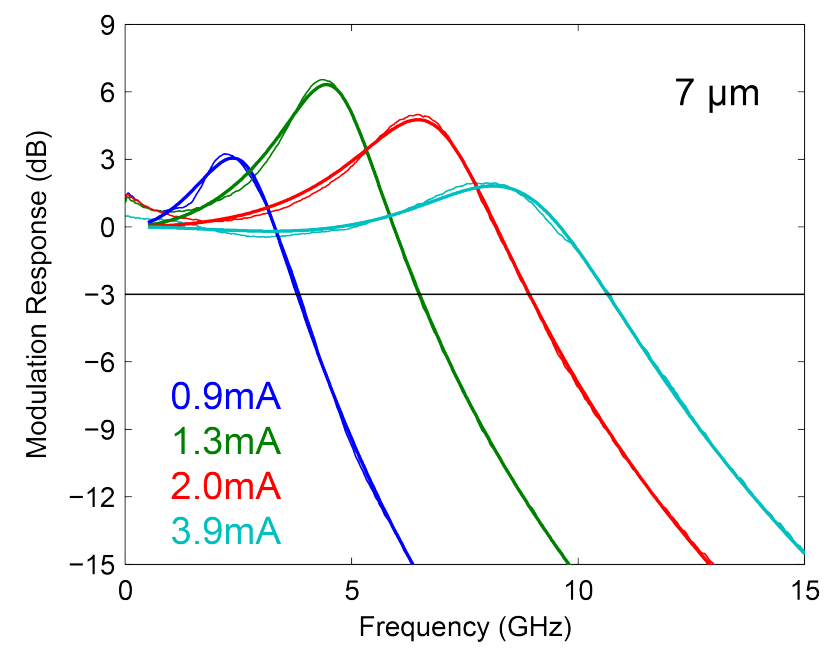

(c)

Fig. 3. Small signal modulation response of hybrid-cavity VCSELs with (a) 3, (b) 5, and (c) $7 \mu \mathrm{m}$ oxide aperture diameter at indicated bias currents.

$$
f_{\mathrm{r}}=\frac{1}{2 \pi} \sqrt{\frac{\nu_{\mathrm{g}} \cdot(\partial g / \partial n) \cdot S}{\tau_{\mathrm{p}}}}
$$

where $v_{\mathrm{g}}$ is the group velocity, $\partial g / \partial n$ is the differential gain,

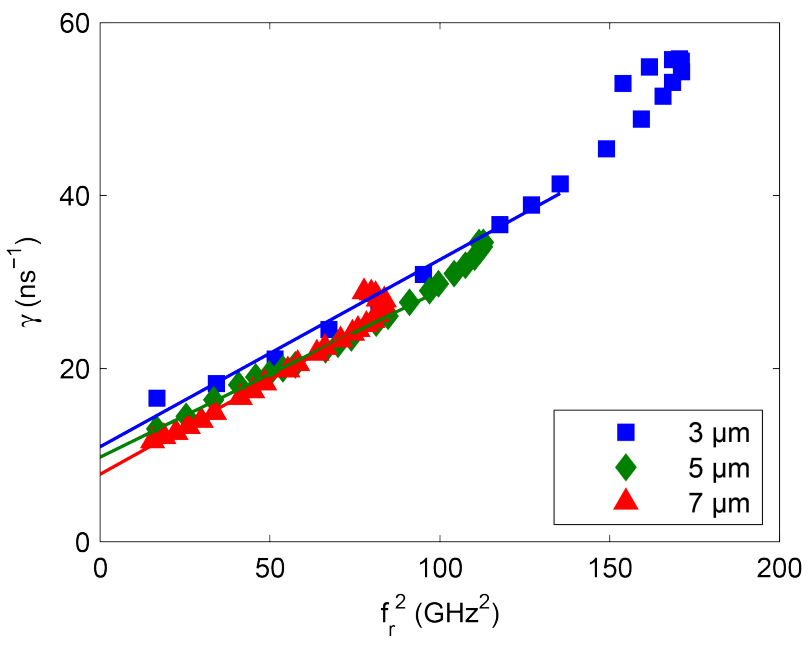

(a)

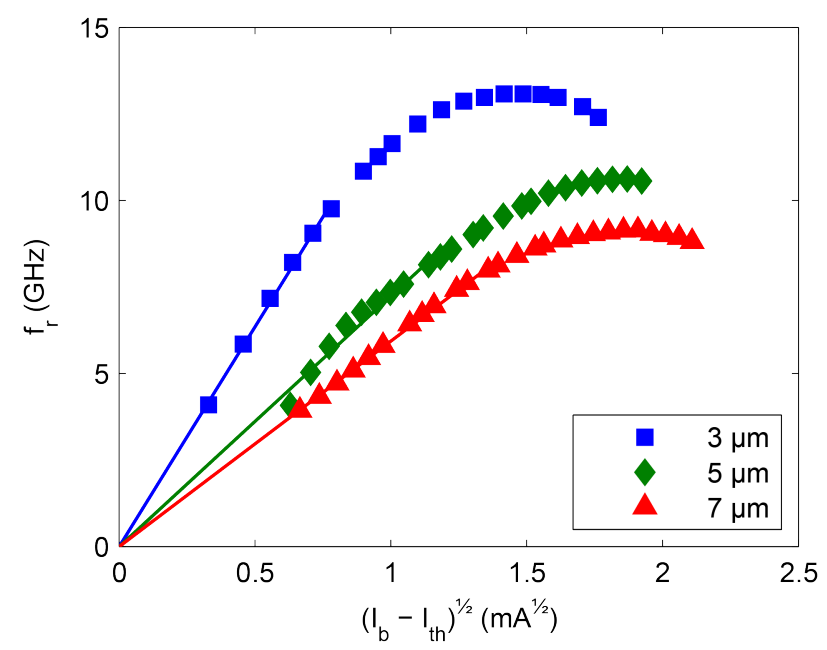

(b)

Fig. 4. (a) Damping rate versus resonance frequency squared, with linear fits to extract the $K$-factors (from the slope). (b) Resonance frequency versus square root of bias current above threshold, with linear fits to extract the $D$-factors (from the slope).

and $\tau_{\mathrm{p}}$ is the photon lifetime, this limits the maximum resonance frequency. Therefore, in addition to parasitics, thermal effects impose a severe limitation on the modulation bandwidth.

For a conventional GaAs-based oxide-confined VCSEL, a $K$-factor of $0.2 \mathrm{~ns}$ would provide enough damping for a flat modulation response at high currents [9]. However, the present VCSELs exhibit significant peaking in the response also at high currents, as seen in Fig. 3. This again stems from the limited maximum photon density and resonance frequency (by the early onset of the thermal rollover), as the damping rate $(\gamma)$ increases with resonance frequency according to [12]

$$
\gamma=K \cdot f_{\mathrm{r}}^{2}+\gamma_{0}
$$

where $\left(\gamma_{0}\right)$ is the damping offset. This imposes a limitation on the achievable bit rate under large signal modulation as the resonant response causes overshoot and ringing, which in turn translates into timing jitter and horizontal eye closure [9]. The smallest aperture VCSEL has a more damped response (Fig. 3a), but its low output power limits the optical 


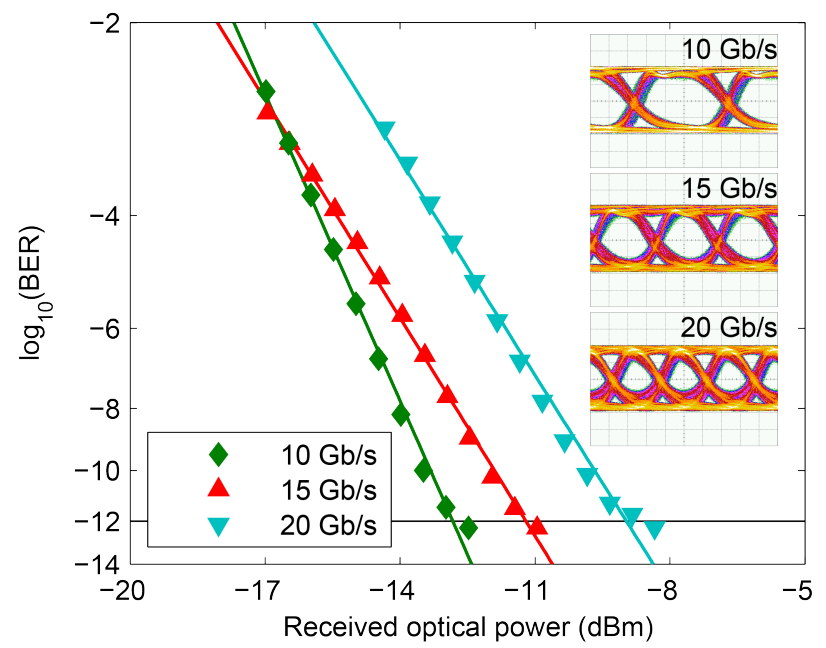

Fig. 5. BER measurements at 10,15 , and $20 \mathrm{~Gb} / \mathrm{s}$ for a hybrid-cavity VCSEL with $5 \mu \mathrm{m}$ oxide aperture diameter biased at $3.5 \mathrm{~mA}$. Insets: Corresponding eye diagrams. Scales: $100 \mathrm{mV} / \mathrm{div}$ and $20 \mathrm{ps} / \mathrm{div}$.

modulation amplitude, resulting in vertical eye closure at high bit rates.

\section{DATA TRANSMisSiON}

The $5 \mu \mathrm{m}$ oxide aperture VCSEL was used for large signal modulation and data transmission since it provides sufficiently high optical output power and has a moderately damped small signal modulation response. A non-return-to-zero signal consisting of pseudorandom binary sequences (PRBS) with word length $2^{7}-1$, generated by a bit pattern generator (SHF 12103A), was fed to the VCSEL through the high-speed bias$\mathrm{T}$ and the high-speed RF probe. The output light was coupled to an OM4 multimode optical fiber using a lens package. The fiber was connected to a $30 \mathrm{GHz}$ limiting photoreceiver (VI Systems R40-850) via a variable optical attenuator (EXFO FVA-3150). The photoreceiver was either connected to an error analyzer (SHF 11100B) to measure the bit error rate (BER) or a $70 \mathrm{GHz}$ equivalent time sampling oscilloscope (Agilent Infiniium DCA-J 86100C) to record eye diagrams. With a bias current of $3.5 \mathrm{~mA}$, error-free transmission (defined as $\mathrm{BER}<10^{-12}$ ) was possible up to $20 \mathrm{~Gb} / \mathrm{s}$. The BER versus received optical power at 10,15 , and $20 \mathrm{~Gb} / \mathrm{s}$ and the corresponding eye diagrams are shown in Fig. 5. The bias current is close to the thermal rollover current, which is needed for a sufficiently high bandwidth and sufficient damping. Even so, the resonant behavior causes overshoot in the optical signal, which translates into timing jitter in the limiting photoreceiver [9].

\section{CONCLUSION}

We have presented results from a study of the dynamic characteristics of 850-nm-wavelength hybrid-cavity VCSELs heterogeneously integrated on silicon using DVS-BCB adhesive bonding. A $5 \mu \mathrm{m}$ oxide aperture VCSEL has a $3 \mathrm{~dB}$ modulation bandwidth exceeding $11 \mathrm{GHz}$, mainly limited by thermal effects and parasitics. While the capacitance can be reduced by adding additional oxide layers in future designs, the thermal effects impose a more severe limitation. This calls for proceeding investigations of e.g. the use of integrated metallic heat spreaders for improved thermal performance. Still, the hybrid-cavity VCSEL was shown to support $20 \mathrm{~Gb} / \mathrm{s}$ data transmission.

\section{REFERENCES}

[1] E. Haglund, P. Westbergh, J. S. Gustavsson, E. P. Haglund, A. Larsson, M. Geen, and A. Joel, " $30 \mathrm{GHz}$ bandwidth $850 \mathrm{~nm}$ VCSEL with sub$100 \mathrm{fJ} /$ bit energy dissipation at 25-50 Gbit/s," Electron. Lett., vol. 51, no. 14, pp. 1096-1098, 2015.

[2] D. M. Kuchta, A. V. Rylyakov, F. E. Doany, C. L. Schow, J. E. Proesel, C. W. Baks, P. Westbergh, J. S. Gustavsson, and A. Larsson, "A 71Gb/s NRZ Modulated 850-nm VCSEL-Based Optical Link," IEEE Photonics Technol. Lett., vol. 27, no. 6, pp. 577-580, Mar. 2015.

[3] P. Moser, J. A. Lott, P. Wolf, G. Larisch, H. Li, N. N. Ledentsov, and D. Bimberg, "56 fJ dissipated energy per bit of oxide-confined $850 \mathrm{~nm}$ VCSELs operating at $25 \mathrm{Gbit} / \mathrm{s}$," Electron. Lett., vol. 48, no. 20, p. 1292, 2012.

[4] Y. Tsunemi, N. Yokota, S. Majima, K. Ikeda, T. Katayama, and H. Kawaguchi, "1.55- $\mu \mathrm{m}$ VCSEL with polarization-independent HCG mirror on SOI," Opt. Express, vol. 21, no. 23, p. 28685, Nov. 2013.

[5] J. Ferrara, L. Zhu, W. Yang, P. Qiao, and C. J. Chang-Hasnain, "Heterogeneously-integrated VCSEL using high-contrast grating on silicon," in Proc. SPIE, 2015, vol. 9372, p. 937208.

[6] E. P. Haglund, S. Kumari, P. Westbergh, J. S. Gustavsson, G. Roelkens, R. Baets, and A. Larsson, "Silicon-Integrated Short-Wavelength HybridCavity VCSEL," Submitt. to Opt. Express, 2015.

[7] S. Keyvaninia, M. Muneeb, S. Stanković, P. J. Van Veldhoven, D. Van Thourhout, and G. Roelkens, "Ultra-thin DVS-BCB adhesive bonding of III-V wafers, dies and multiple dies to a patterned silicon-on-insulator substrate," Opt. Mater. Express, vol. 3, no. 1, p. 35, Jan. 2013.

[8] P. Westbergh, J. S. Gustavsson, B. Kögel, A. Haglund, and A. Larsson, "Impact of Photon Lifetime on High-Speed VCSEL Performance," IEEE J. Sel. Top. Quantum Electron., vol. 17, no. 6, pp. 1603-1613, Nov. 2011.

[9] E. P. Haglund, P. Westbergh, J. S. Gustavsson, and A. Larsson, "Impact of Damping on High-Speed Large Signal VCSEL Dynamics," J. Light. Technol., vol. 33, no. 4, pp. 795-801, Feb. 2015.

[10] P. P. Baveja, B. Kogel, P. Westbergh, J. S. Gustavsson, A. Haglund, D. N. Maywar, G. P. Agrawal, and A. Larsson, "Impact of Device Parameters on Thermal Performance of High-Speed Oxide-Confined 850-nm VCSELs," IEEE J. Quantum Electron., vol. 48, no. 1, pp. 1726, Jan. 2012.

[11] Yang Liu, Wei-Choon Ng, B. Klein, and K. Hess, "Effects of the spatial nonuniformity of optical transverse modes on the modulation response of vertical-cavity surface-emitting lasers," IEEE J. Quantum Electron., vol. 39, no. 1, pp. 99-108, Jan. 2003.

[12] L. Coldren and S. Corzine, Diode Lasers and Photonic Integrated Circuits. New York, NY: John Wiley \& Sons, Inc., 1995.

[13] N. Nishiyama, M. Arai, S. Shinada, K. Suzuki, F. Koyama, and K. Iga, "Multi-oxide layer structure for single-mode operation in vertical-cavity surface-emitting lasers," IEEE Photonics Technol. Lett., vol. 12, no. 6, pp. 606-608, Jun. 2000.

[14] M. Azuchi, N. Jikutani, M. Arai, T. Kondo, and F. Koyama, "Multioxide layer vertical-cavity surface-emitting lasers with improved modulation bandwidth," in CLEO/Pacific Rim 2003. The 5th Pacific Rim Conference on Lasers and Electro-Optics (IEEE Cat. No.03TH8671), 2003, vol. 1, no. 2, pp. 163-163.

[15] Y. C. Chang, C. S. Wang, L. A. Johansson, and L. A. Coldren, "Highefficiency, high-speed VCSELs with deep oxidation layers," Electron. Lett., vol. 42, no. 22, p. 1281, 2006. 